\title{
Neuroendocrine neoplasms of the lung: a pathology update
}

\author{
Jasna Metovic · Marco Barella $\cdot$ Giuseppe Pelosi $(\mathbb{D}$
}

Received: 18 November 2020 / Accepted: 11 January 2021 / Published online: 21 May 2021

(C) The Author(s) 2021

\begin{abstract}
Summary
Purpose Neuroendocrine tumors and neuroendocrine carcinomas in the lung are distinct and separate entities featuring neuroendocrine differentiation, for which an accurate classification is clinically warranted.

Materials and methods Three perspectives were addressed: (i) diagnostic tools, with the terminology to be used in either resection specimen or small-sized material; (ii) the so-called carcinoid tumors with elevated proliferation rates (mitotic and/or Ki-67 activity); (iii) predictive biomarkers based on immunohistochemical characterization.

Results We herein provide a pathology update on lung neuroendocrine neoplasm classification that will appear in the forthcoming 5 th edition of the WHO Blue Book, including a short discussion about biomarkers, which are presently given full consideration in clinical practice.

Conclusion The WHO classification on lung neuroendocrine neoplasms is the cornerstone to provide the best clinical management of patients and is the starting point for any investigative insight.
\end{abstract}

Keywords Prognosis - Predictive biomarker . Diagnosis · Tumor progression · Paradigm shift

\section{Dr. J. Metovic, MD}

Department of Oncology, University of Turin, Turin, Italy

Dr. M. Barella, MD · Prof. Dr. G. Pelosi, MD, MIAC (四)

Department of Oncology and Hemato-oncology, University of Milan, Milan, Italy

giuseppe.pelosi@unimi.it

Prof. Dr. G. Pelosi, MD, MIAC

Servizio Interaziendale di Anatomia Patologica, IRCCS MultiMedica, Via Gaudenzio Fantoli 16/15, 20138 Milan, Italy

\section{Introduction}

Lung neuroendocrine neoplasms (NENs) are presently classified as neuroendocrine tumors (NETs), which include low-grade typical carcinoid (TC) and intermediate-grade atypical carcinoid (AC), and neuroendocrine carcinomas (NECs), which include small cell (lung) carcinoma (SCLC) and large cell neuroendocrine carcinoma (LCNEC) ([1]; Fig. 1). A common classification framework was developed by a consensus meeting of experts who met in Lyon (France) in 2017 under the aegis of the WHO and the International Agency for Research on Cancer (IARC), taking also the cue from the European Neuroendocrine Tumor Society (ENETS) terminology used in gastroenteropancreatic NENs [2]. This scheme will be also extended to the forthcoming new 5th edition of the World Health Organization (WHO) classification on lung NENs. Accordingly, TC and AC are said to correspond to G1 and G2 well-differentiated NETs, while SCLC and LCNEC are poorly differentiated fullfledged NECs tautologically merging within G3 tumors [3].

Diagnostic criteria of lung NENs comprise mitotic count on $2 \mathrm{~mm}^{2}$, necrosis evaluation and a constellation of cytohistological and immunohistochemistry traits, which have been maintained over the last three WHO classifications [1, 4, 5] and will be extended to the forthcoming new 5th edition of the WHO Blue Book (Fig. 2). Carcinoids, whether TC or AC, may show diverse architectural patterns and/or cellular variants which are clinically irrelevant. The association of carcinoids with non-small cell carcinoma (NSCC), such as adenocarcinoma or squamous cell carcinoma, is anecdotal $[1,6]$. Rare tumors presenting with a component of low-grade NET and high-grade NEC are molecularly akin to the so-called carcinoidlike LCNEC [7], are currently classified as LCNEC [1] 


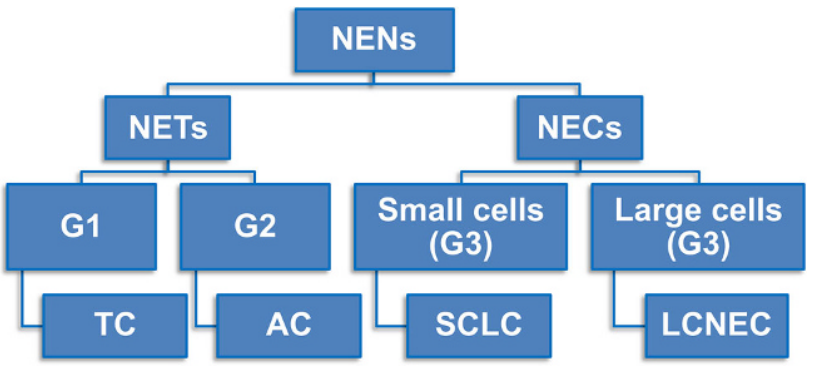

Fig. 1 Classification of lung neuroendocrine neoplasms (NENs). They include well-differentiated neuroendocrine tumors (NETs) and poorly differentiated neuroendocrine carcinomas (NECs). NETs in turn comprise low-grade G1 typical carcinoid (TC) and intermediate-grade G2 atypical carcinoid (AC), whereas NECs are tautologically G3 neoplasms with either small (SCLC) or large (LCNEC) cells. G1 corresponds to well differentiated, G2 corresponds to intermediately differentited, G3 corresponds to poorly differentiated

and closely merge within carcinoids with elevated proliferation rates [8]. The clinical behavior of carcinoids remains basically dictated by mitoses and necrosis, according to which TC are low malignant tumors (G1) with an excellent long-term prognosis and AC intermediate malignant tumors (G2) with an increased rate of distant metastases and less favorable prognosis [9]. Conversely, one fourth to one third of SCLC and LCNEC exhibit additional components of NSCC, which embody the so-called combined vari- ants sharing the same poor prognosis as the pure forms with the highest likelihood of lymph node and visceral metastases [1]. The term mixed neuroendocrine-nonneuroendocrine neoplasms (MINENs), which is used in the gastroenteropancreatic tract [10-12], is not recommended in the lung to indicate combined variants according to the new 5 th edition of the WHO classification.

Herein, we shortly review recent advances in the classification of lung NENs by focusing on challenging diagnostic issues and predictive immunohistochemical biomarkers.

\section{Diagnostic tools}

The diagnosis of lung NENs is prerequisite for any adequate clinical decision-making process, but sometimes is demanding in small-sized diagnostic material. The entire spectrum of tumors can be envisaged in resection specimens only, where mitotic count, necrosis and cytohistological details are reproducibly assessed although there is some interobserver variability due to the subjective application of defining criteria. In this regard, refining methods of counting mitoses as outlined in the forthcoming 5th edition of the WHO Blue Book may improve the ultimate diagnoses, especially when dealing with NETs. The proliferation marker Ki67 expressed as labeling index in hot spot tumor areas does not have a direct diagnostic inference to split the

Fig. 2 Histologic picture of typical carcinoid with no mitotic activity (a), atypical carcinoid with at least two mitoses in the field (dotted circles) (b) and large cell neuroendocrine carcinoma with many mitoses and prominent nucleoli (c). Small cell carcinoma is hallmarked by small-sized cells with plentiful mitoses (not discernible at this magnification) in a fibrotic stroma (d)
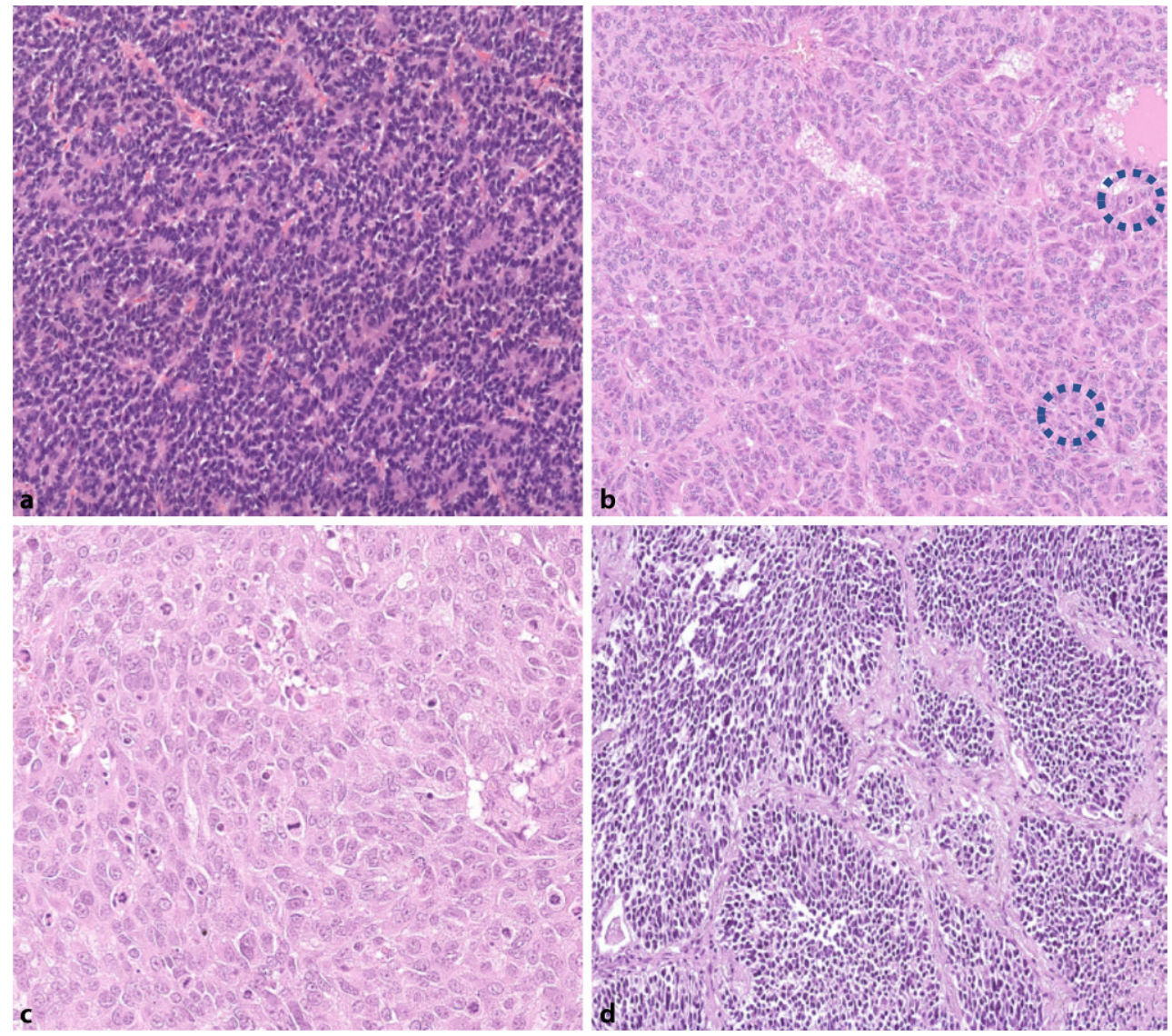
diverse categories of lung NENs [13]. In fact, Ki-67 is inconsistently associated with histologic classification due to its nonlinear correlation with mitotic activity and necrosis, and limited interobserver reproducibility, which results in some overlap between various adjacent diagnostic categories (TC vs. AC; AC vs. LCNEC/SCLC; LCNEC vs. SCLC) [13]. Conversely, this marker is particularly helpful to avoid overdiagnosing TC or AC as SCLC or LCNEC in small-sized diagnostic material, especially with crush artifacts, thereby excluding major pitfalls in the management of patients (NETs are treated differently than NECs) [14]. Although combining Ki-67 with mitotic count and necrosis has been proposed as a more effective prognosticator than standalone morphology especially at the level of an individual patient's cancer [15], grading of lung NENs is still based on the histological classification [1] and even the new WHO classification will affirm this premise. Proposed rates of Ki-67 ranged from $2.3-4.15 \%$ in TC (mean $2.60 \%$ ), $9-17.8 \%$ in AC (mean $11.04 \%$ ), 47.5-70.0\% in LCNEC (mean $47.57 \%$ ), and $64.5-77.5 \%$ in SCLC (mean $64.36 \%$ ), in substantial agreement with the expected proliferation activity of these tumors [13]. The upper limits of 5\% and 30\% for Ki-67 have been conceived to differentiate TC from $\mathrm{AC}$ and AC from NECs, respectively, with a better performance over mitotic count and/or necrosis in small-sized diagnostic material [16].

A more simplified terminology should be applied to cytology/biopsy samples. TC and AC are clustered together as carcinoids and LCNEC is only suggested as a possible option of diagnosis in the presence of NE morphology. The implementation of immunohistochemistry for NE markers, however, could increase recognition of LCNEC if consistent positive staining is found in at least two out of three NE markers even while lacking the obvious NE appearance [17]. Conversely, SCLC is the most readily diagnosed tumor on this material type, inasmuch as largely based on cytological details rather than neuroendocrine biomarkers, which are missing in about $10 \%$ of instances [18]. The use of immunohistochemistry may, however, improve the diagnosis of SCLC and its differential diagnosis in clinical practice, especially in the presence of crush artifacts [19].

In metastatic sites sampled by core biopsy or cytology, it is recommended to not force a diagnosis of TC or AC whenever morphology of carcinoid is retained, but simply rendering the diagnosis of "metastatic carcinoid tumor" and detailing mitotic count, necrosis amount and Ki-67 labeling index. The latter is particularly useful to give an immediate evaluation of tumor cell proliferation because the identification of mitoses may be demanding in certain types of material. In fact, Ki-67 evaluation has proven to be more reliable than mitoses and necrosis in paired biopsy samples and surgical specimens [16] or in biopsies of metastatic lung carcinoids for the clinical decisionmaking process [20].
Table 1 Comparative classification of gastrointestinal/ pancreatic and pulmonary neuroendocrine neoplasms (NENs)

\begin{tabular}{llll} 
Grading & \multicolumn{1}{l}{$\begin{array}{l}\text { Neuroendocrine } \\
\text { differentiation }\end{array}$} & $\begin{array}{l}\text { Gastrointestinal } \\
\text { tract and pancreas }\end{array}$ & Lung \\
$\begin{array}{l}\text { Low grade } \\
\text { (G1) }\end{array}$ & WD & NET G1 & Typical carcinoid G1 \\
$\begin{array}{l}\text { Intermediate } \\
\text { grade (G2) }\end{array}$ & WD & NET G2 & Atypical carcinoid G2 \\
$\begin{array}{l}\text { High grade } \\
\text { (G3) }\end{array}$ & WD & NET G3 & $\begin{array}{l}\text { Carcinoid with in- } \\
\text { creased proliferation } \\
\text { rates }\end{array}$ \\
& PD & $\begin{array}{l}\text { NEC, small cell } \\
\text { pure and MINEN } \\
\text { NEC, large cell } \\
\text { pure and MINEN }\end{array}$ & $\begin{array}{l}\text { NEC, small cell (SCLC) } \\
\text { pure and combined }\end{array}$ \\
\hline & $\begin{array}{l}\text { NEC, large cell (LCNEC) } \\
\text { pure and combined }\end{array}$ \\
\hline
\end{tabular}

WD well differentiated, $P D$ poorly differentiated, NEC neuroendocrine carcinoma, MINEN mixed neuroendocrine-nonneuroendocrine neoplasm, SCLC small cell lung carcinoma, LCNEC large cell neuroendocrine carcinoma

\section{Carcinoid tumors with elevated proliferation}

There are uncommon lung NENs featuring LCNEC or, rarely, SCLC that exhibit carcinoid architecture (i.e., morphology of well-differentiated NETs) but increased mitotic count exceeding the allowed limit of 10 mitoses per $2 \mathrm{~mm}^{2}$ and/or more extensive necrosis (rather than being typically punctate in AC) $[7,8]$. These carcinoids with elevated proliferation exhibit a Ki-67 labeling index greater than $30 \%$, which exceeds by far what one would expect from NETs. In the resection specimens these instances are rare and are classified as LCNEC by the current defining criteria [7], thereby maintaining the same interpretation as in the 1999 WHO classification [5]. However, carcinoids of the lung with elevated proliferation have been more frequently documented in metastatic sites, whether synchronous or metachronous [8], which would correspond to NET G3 of the gastroenteropancreatic tract $[11,12]$. These tumors in the lung will be termed as carcinoid tumors with elevated mitotic count and/or Ki-67 proliferation rates in the forthcoming 5 th edition of the WHO Blue Book while further knowledge and experience in clinical practice is awaited. An interesting hypothesis has been made about how these carcinoids with an increased mitotic count and $\mathrm{Ki}$ 67 labeling rates might develop: not only spontaneous tumorigenesis but also due to therapy-induced mechanisms of tumor progression $[6,21]$. A comparative synopsis of NEN classification between the gastroenteropancreatic tract and the lung is presented in Table 1.

\section{Predictive biomarkers}

As resection specimens and/or biopsy/cytology samples are increasingly available for lung NENs in clinical practice, an increasing number of predictive markers can be identified by means of immunohistochemistry. Currently, immunohistochemistry tests should 
not be routinely carried out in lung NENs according to current guidelines. However, awareness of these tests may prove to be useful in specific study protocols to diversify therapy options in challenging clinical situations [22, 23]. This holds true for lifethreatening NECs in an attempt to improve prognosis and life expectancy. Practical examples include the achaete-scute family BHLH transcription factor 1 (ASCL1), an indicator of non-variant subtypes of SCLC, which predicts susceptibility to chemotherapy $[18,24]$, or programmed death-ligand 1 (PD-L1) or CD274, an immune checkpoint negative regulator suppressing the adaptive arm of immune system, as a managerial marker for the treatment with specific immune checkpoint inhibitors of both SCLC [25] or LCNEC [26]. Lastly, delta-like ligand 3 (DLL3), an inhibitory notch ligand, is presently being explored as a potential target for the antibody-drug conjugate rovalpituzumab tesirine, the bispecific $\mathrm{T}$ cell engager immuno-oncology therapy AMG 757 or the chimeric antigen receptor T cell therapy AMG 119 in SCLC [27] or LCNEC [28]. Similar considerations may be applied to thymidylate synthase (TS) nuclear expression as a valuable predictor of antifolate drug sensitivity in NECs of either small or large cells [29, 30]. Most carcinoids are surgically treated but in a metastatic setting the assessment of mammalian target of rapamycin (mTOR) may be used as a predictor of treatment with specific inhibitors, such as everolimus [31] or somatostatin receptor evaluation for planning peptide receptor radionuclide therapy $[32,33]$.

\section{Take home messages}

- The WHO classification of lung NENs is the cornerstone for the best clinical management of patients.

- Refining terminology and diagnostic criteria (mitoses, necrosis, Ki-67) in surgical specimens and smallsized tissue material has resulted in the introduction of a new category of carcinoids characterized by elevated mitotic count and/or Ki-67 proliferation activity, whose oncological implications still need further research.

- Several immunohistochemical biomarkers are presently given thorough consideration in oncology practice to improve prognosis and survival of patients with life-threatening neuroendocrine neoplasms.

Acknowledgements This work is dedicated to the memory of Carlotta, an extraordinarily lively girl who died an untimely death due to cancer in the prime of her life. The authors are indebted with Ms. Cecilia Pelosi for accurate proofreading of the manuscript.

Author Contribution GP conceived and designed the review, drafted and finalized the manuscript; JM designed the study, drafted and finalized the manuscript; MB critically revised and finalized the manuscript. All authors approved the submitted version.
Funding Open Access funding provided by Università degli Studi di Milano

\section{Compliance with ethical guidelines}

Conflict of interest J. Metovic, M. Barella and G. Pelosi declare that they have no competing interests.

Ethical standards This is a review article on already existing literature data, thus no approval by Internal Review Board was required.

Open Access This article is licensed under a Creative Commons Attribution 4.0 International License, which permits use, sharing, adaptation, distribution and reproduction in any medium or format, as long as you give appropriate credit to the original author(s) and the source, provide a link to the Creative Commons licence, and indicate if changes were made. The images or other third party material in this article are included in the article's Creative Commons licence, unless indicated otherwise in a credit line to the material. If material is not included in the article's Creative Commons licence and your intended use is not permitted by statutory regulation or exceeds the permitted use, you will need to obtain permission directly from the copyright holder. To view a copy of this licence, visit http://creativecommons.org/licenses/by/4.0/.

\section{References}

1. Travis W, Brambilla E, Burke A, Marx A, Nicholson A. WHO classification of tumours of the lung, pleura, thymus and heart. Lyon: IARC; 2015.

2. Rindi G, Klersy C, Albarello L, Baudin E, Bianchi A, Buchler MW, et al. Competitive testing of the WHO 2010 versus the WHO 2017 grading of pancreatic neuroendocrine neoplasms: data from a large international cohort study. Neuroendocrinology. 2018;107:375-86. https://doi.org/ $10.1159 / 000494355$.

3. Rindi G, Klimstra DS, Abedi-Ardekani B, Asa SL, Bosman FT, Brambilla $\mathrm{E}$, et al. A common classification framework for neuroendocrine neoplasms: an International Agency for Research on Cancer (IARC) and World Health Organization (WHO) expert consensus proposal. Mod Pathol. 2018;31:1770-86. https://doi.org/10.1038/s41379018-0110-y.

4. Travis W, Brambilla E, Muller-Hermelink H, Harris C. Tumours of the lung, pleura, thymus and heart. Lyon: IARC; 2004.

5. Travis W, Colby T, Corrin B, Shimosato Y, Brambilla E. Hystological typing of lung and pleural tumours. Berlin, Heidelberg, New York: Springer; 1999.

6. Pelosi G, Bianchi F, Hofman P, Pattini L, StrobelP, CalabreseF, et al. Recent advances in the molecular landscape of lung neuroendocrine tumors. Expert Rev Mol Diagn. 2019;19:281-97. https://doi.org/10.1080/14737159.2019. 1595593.

7. RekhtmanN,PietanzaMC,HellmannMD, NaidooJ,AroraA, Won $\mathrm{H}$, et al. Next-generation sequencing of pulmonary large cell neuroendocrine carcinoma reveals small cell carcinoma-like and non-small cell carcinoma-like subsets. Clin Cancer Res. 2016;22:3618-29. https://doi.org/10. 1158/1078-0432.CCR-15-2946.

8. Rekhtman N, Desmeules P, Litvak AM, Pietanza MC, Santos-Zabala ML, Ni A, et al. Stage IV lung carcinoids: spectrum and evolution of proliferation rate, focusing 
on variants with elevated proliferation indices. Mod Pathol. 2019;32:1106-22. https://doi.org/10.1038/s41379019-0248-2.

9. Pelosi G, Fabbri A, Cossa M, Sonzogni A, Valeri B, Righi L, et al. What clinicians are asking pathologists when dealing withlungneuroendocrineneoplasms? Semin Diagn Pathol. 2015;32:469-79. https://doi.org/10.1053/j.semdp.2015.10. 009.

10. La Rosa S, Sessa F, Uccella S. Mixed neuroendocrine-nonneuroendocrine neoplasms (MiNENs): unifying the concept of a heterogeneous group of neoplasms. Endocr Pathol. 2016;27:284-311. https://doi.org/10.1007/s12022016-9432-9.

11. WHO Classification of Tumours Editorial Board. Digestive system tumours. WHO classification of tumours, Vol. 1 . Lyon: IARC; 2019.

12. Lloyd R, Osamura R, Klöppel G, Rosai J. WHO classification of tumours of endocrine organs. Lyon: IARC; 2017.

13. Pelosi G, Rindi G, Travis WD, Papotti M. Ki-67 antigen in lung neuroendocrine tumors: unraveling a role in clinical practice. J Thorac Oncol. 2014;9:273-84. https://doi.org/10. 1097/JTO.000000000000009201243894-201403000-00004.

14. Pelosi G, Rodriguez J, Viale G, Rosai J. Typical and atypical pulmonary carcinoid tumor overdiagnosed as smallcell carcinoma on biopsy specimens: a major pitfall in the management of lung cancer patients. Am J Surg Pathol. 2005;29:179-87. https://doi.org/10.1097/01.pas. 0000149690.75462 .29 .

15. Rindi G, Klersy C, Inzani F, Fellegara G, Ampollini L, Ardizzoni A, et al. Grading the neuroendocrine tumors of the lung: an evidence-based proposal. Endocr Relat Cancer. 2013;21(1):1-16. https://doi.org/10.1530/ERC-13-0246.

16. Fabbri A, Cossa M, Sonzogni A, Papotti M, Righi L, Gatti G, et al. Ki-67 labeling index of neuroendocrine tumors of the lung has a high level of correspondence between biopsy samples and surgical specimens when strict countingguidelines areapplied. Virchows Arch. 2017;470:153-64. https://doi.org/10.1007/s00428-016-2062-2.

17. Derks JL, Dingemans AC, van Suylen RJ, den Bakker MA, Damhuis RAM, van den BroekEC, etal. Is the sum of positive neuroendocrine immunohistochemical stains useful for diagnosis of large cell neuroendocrine carcinoma (LCNEC) on biopsy specimens? Histopathology. 2019;74:555-66. https://doi.org/10.1111/his.13800.

18. Rudin CM, Poirier JT, Byers LA, Dive C, Dowlati A, George J, et al. Molecular subtypes of small cell lung cancer: a synthesis of human and mouse model data. Nat Rev Cancer. 2019;19:289-97. https://doi.org/10.1038/s41568-0190133-9.

19. Thunnissen E, BorczukAC, Flieder DB, Witte B, Beasley MB, Chung JH, et al. The use of immunohistochemistry improves the diagnosis of small cell lung cancer and its differential diagnosis. An international reproducibility study in a demanding set of cases. J Thorac Oncol. 2017;12:334-46. https://doi.org/10.1016/j.jtho.2016.12.004.

20. Pelosi G, Massa F, Gatti G, Righi L, Volante M, Birocco N, et al. Ki-67 evaluation for clinical decision in metastatic lung carcinoids: a proof of concept. Clin Pathol. 2019;12:2632010X19829259. https://doi.org/10.1177/ $2632010 X 19829259$.

21. Pelosi G, Bianchi F, Dama E, Simbolo M, Mafficini A, Sonzogni A, et al. Most high-grade neuroendocrine tumours of the lung are likely to secondarily develop from pre-existing carcinoids: innovative findings skipping the current pathogenesis paradigm. Virchows Arch. 2018;472:567-77. https://doi.org/10.1007/s00428-018-2307-3.
22. Caplin ME, Baudin E, Ferolla P, Filosso P, Garcia-Yuste M, Lim E, et al. Pulmonary neuroendocrine (carcinoid) tumors: European Neuroendocrine Tumor Society expert consensus and recommendations for best practice for typical and atypical pulmonary carcinoids. Ann Oncol. 2015;26:1604-20. https://doi.org/10.1093/annonc/ mdv041.

23. Hendifar AE, Marchevsky AM, Tuli R. Neuroendocrine tumors of the lung: current challenges and advances in the diagnosis and management of well-differentiated disease. JThorac Oncol. 2017;12:425-36. https:// doi.org/10.1016/j. jtho.2016.11.2222.

24. Zhang W, Girard L, Zhang YA, Haruki T, Papari-Zareei M, StastnyV, etal. Small cell lung cancer tumors and preclinical models display heterogeneity of neuroendocrine phenotypes. Transl Lung Cancer Res. 2018;7:32-49. https://doi. org/10.21037/tlcr.2018.02.02.

25. Konala VM, Madhira BR, Ashraf S, Graziano S. Use of immunotherapy in extensive-stage small cell lung cancer. Oncology. 2020;98(11):749-54. https://doi.org/10.1159/ 000508516.

26. Sherman S, Rotem O, Shochat T, Zer A, Moore A, Dudnik E. Efficacy of immune check-point inhibitors (ICPi) in large cell neuroendocrine tumors of lung (LCNEC). Lung Cancer. 2020;143:40-6. https://doi.org/10.1016/j.lungcan. 2020.03.008.

27. Owen DH, Giffin MJ, Bailis JM, Smit MD, Carbone DP, He K. DLL3: an emerging target in small cell lung cancer. J Hematol Oncol. 2019;12:61. https://doi.org/10.1186/ s13045-019-0745-2.

28. Hermans BCM, Derks JL, Thunnissen E, van Suylen RJ, den Bakker MA, Groen HJM, et al. DLL3 expression in large cell neuroendocrine carcinoma (LCNEC) and association with molecular subtypes and neuroendocrine profile. Lung Cancer. 2019;138:102-8. https://doi.org/10.1016/j. lungcan.2019.10.010.

29. Monica V, Scagliotti GV, Ceppi P, Righi L, Cambieri A, Lo Iacono M, et al. Differential thymidylate synthase expression in different variants of large-cell carcinoma of the lung. Clin Cancer Res. 2009;15:7547-52. https://doi. org/10.1158/1078-0432.CCR-09-1641.

30. Righi L, Volante M, Rapa I, Vatrano S, Pelosi G, Papotti M. Therapeutic biomarkersinlungneuroendocrineneoplasia. Endocr Pathol. 2014;25:371-7. https://doi.org/10.1007/ s12022-014-9335-6.

31. ZhangZ, Wang M.PI3K/AKT/mTOR pathway in pulmonary carcinoid tumours. Oncol Lett. 2017;14:1373-8. https:// doi.org/10.3892/ol.2017.6331.

32. Righi L, Volante M, Tavaglione V, Bille A, Daniele L, Angusti $\mathrm{T}$, et al. Somatostatin receptor tissue distribution in lung neuroendocrine tumours: a clinicopathologic and immunohistochemical study of 218 'clinically aggressive' cases. Ann Oncol. 2010;21:548-55. https://doi.org/10. 1093/annonc/mdp334.

33. VolanteM, Brizzi MP, FaggianoA, La RosaS, RapaI, FerreroA, et al. Somatostatin receptor type $2 \mathrm{~A}$ immunohistochemistry in neuroendocrine tumors: a proposal of scoring system correlated with somatostatin receptor scintigraphy. Mod Pathol. 2007;20:1172-82. https://doi.org/10.1038/ modpathol.3800954.

Publisher's Note Springer Nature remains neutral with regard to jurisdictional claims in published maps and institutional affiliations. 